\title{
From West to East to West: A Case Study on Japanese Wine Manga Translated in French
}

Author of a dozen reputable works on wine, M. Dovaz composed the foreword for the French translation of the Japanese graphic novel, Kami no Shizuku (2005), released in France as Les Gouttes de Dieu (2008). This manga has become a best-seller in its genre in France while the Japanese television adaptation has also reached a French audience through fansubs, allowing a new generation to gain access to that which had hitherto been seen as its own cultural patrimony. Integral to this wine culture is the ability to "talk about" its central object, in spite of linguistic or geographical separation. The central challenge being to efficiently associate words to a fleeting sensation provoked by visual, olfactory and gustative experience, a specific linguistic knowledge is necessary for those who wish to claim proficiency in wine. The critical narrative arc and didacticism of wine manga rests in the mastery of lexical sophistication as well as cultural knowledge, a posture also shared by most French experts.

The language of wine, the power center of which once resided in France, has been brought into Japan through the act of translation. This very act has allowed for a shift in power-and thus the potential to represent the wine world-from France to Japan. We will show in this paper that there is an interplay occurring between French and Japanese media, producing a cultural space bridged through wine lexicon used in two series of manga recently translated into French (Sommelier in 2004 and Les Gouttes de Dieu in 2008). For this purpose, we will proceed to a comparative analysis of the Japanese source text with the French target text, highlighting metaphors used in wine culture. Through the analysis of the texts, we will demonstrate that the Japanese-French translations of these metaphors allow a new way for the French to see their culture through a lense provided by the Japanese sommelier. 